\title{
EDITORIALS
}

\section{Sodium Intake and Mortality: The Debate Continues}

\author{
Daniel T. Lackland, DrPH and Brent M. Egan, MD \\ Department of Biostatistics, Bioinformatics and Epidemiology, Medical University of South Carolina, Charleston, SC, USA.
}

J Gen Intern Med 23(9):1537-8

DOI: $10.1007 / \mathrm{s} 11606-008-0743-5$

(c) Society of General Internal Medicine 2008

$\mathrm{D}$ ietary patterns have long been recognized as a key factor in the association of disease patterns and health outcomes. Pellagra, as an example, was prevalent among the poor in the American South in the early 1900s and was basically eradicated with nutritious diets and vitamin-enriched flour. ${ }^{1,2}$ Other conditions such as scurvy are well recognized as associated with diet and malnutrition, and recognized currently in developing countries. ${ }^{3}$ Similarly, the high intake of dietary cholesterol and fats was found decades ago to be associated with increased risks of cardiovascular disease. ${ }^{4,5}$ These findings have led to public health interventions and policies designed to improve dietary patterns in an effort to promote health and prevent disease.

The dietary intake of salt and sodium represents another major lifestyle and behavior associated with disease prevalence. The associations of sodium intake and adverse cardiovascular outcomes have long been recognized, with reduction in salt consumption considered a major public health intervention. Reduction in sodium intake is a recommended lifestyle modification of the Seventh Report of the Joint National Committee on Prevention, Detection, Evaluation, and Treatment of High Blood Pressure: (JNC 7 report) ${ }^{6}$ for all stages of elevated blood pressure. In many clinical investigations, sodium reduction was associated with blood pressure lowering among hypertensives, both alone and as a complement to medical treatment. ${ }^{7}$

The information regarding the risks of high sodium intake and the potential benefit of a lower sodium diet has been conveyed effectively to the public. In a study of older Americans regarding attitudes on lifestyle and blood pressure level, 90\% of the respondents reported that a reduction in salt intake was effective for treating and controlling high blood pressure, with $14 \%$ indicating sodium restriction as the most effective lifestyle factor. ${ }^{8}$ However, with a society skeptical of strategies that fail to yield proclaimed benefits, it is prudent for clinical investigators and epidemiologists to quantify accurate risks and benefits. In this issue of the Journal of General Internal Medicine, Cohen and colleagues continue the debate regarding the risks and benefits of salt intake. ${ }^{9}$ In particular, the authors assess cardiovascular disease and all-cause mortality in the Third National Health and Nutrition Examination Survey (NHANES III) determining modest and non-significant association of sodium intake and higher mortality risks. Further, they concluded from the analyses that higher sodium intake

Published online July 29, 2008 was unlikely to be an independent predictor of high cardiovascular or all-cause mortality. ${ }^{9}$

While the analyses are reasonable and take advantage of a valuable epidemiologic data base, several issues should be considered when evaluating the results. First, these results are based on a secondary data analysis. While such results are valuable in developing hypotheses, conclusions are better based on randomized clinical trials. ${ }^{10}$ The assessment of sodium intake is another limitation of the study, as indicated by the authors. The use of a single measure of sodium intake as an indication of salt consumption may indeed not be representative of the true diet. Likewise, this concern is multiplied as there are no sodium excretion measures to validate the intake values. A third issue regards the potential sampling issues of the NHANES III, which was not designed specifically for the measurement of sodium intake in the population. While this is an excellent study cohort, inclusion of individuals with varying geographic and cultural use of salt may not be adequately sampled. These parameters were not included in the statistical models.

When Alderman and colleagues presented earlier work in 1998 with similar findings using the first National Health and Nutrition Examination Survey, ${ }^{11}$ conflicting views were expressed. The spirited exchange of letters identified many of the limitations and cautions described with the current paper, with the references to numerous epidemiological studies reporting the benefits of salt reduction. Thus, the debate continues. However, as the clinical guidelines for disease management and policies regarding sodium are updated, it is imperative these documents be based on actuate information. While the debate is "healthy" for the progress of science, it can be confusing when affecting prevention and disease management strategies.

Corresponding Author: Daniel T. Lackland, DrPH; Department of Biostatistics, Bioinformatics and Epidemiology, Medical University of South Carolina, Charleston, SC 29425, USA (e-mail: lackland@ musc.edu).

\section{REFERENCES}

1. Landska DJ. Stages in the recognition of epidemic pellagra in the United States: 1865-1960. Neurology. 1996;47:829-834.

2. Martin MG, Humphreys ME. Social consequences of disease in the American South, 1900-World War II. South Med J. 2006;99:862-864.

3. Desenclos JC, Berry AM, Padt R, Farah B, Segala C, Nabi M. Epidemiological patterns of scurvy among Ethiopian refugees. Bull WHO. 1989;67:309-316.

4. Stamler J. Diet-related risk factors for human atherosclerosis: hyperlipidemia, hypertension, hyperglycemia-current status. Adv Exp Med Biol. 1975;60:125-158.

5. Kuller LH. Epidemiology of cardiovascular diseases: current perspectives. Am J Epidemiol. 1976;104:425-496.

6. Chobanian AV, Bakris GL, Black HR, et al. The Seventh Report of the Joint National Committee on Prevention, Detection, Evaluation, and 
Treatment of High Blood Pressure: the JNC 7 report. JAMA. 2003;289: 2560-2572.

7. Lackland DT, Egan BM. Dietary salt restriction and blood pressure in clinical trials. Curr Hypertens Rep. 2007;9:314-319.

8. Egan BM, Lackland DT, Cutler NE. Awareness, knowledge, and attitudes of older Americans about high blood pressure: implications for health care policy, education, and research. Arch Intern Med. 2003; 163:681-687.

9. Cohen HW, Hailpern SM, Alderman H. Sodium intake and mortality follow-up in the Third National Health and Nutrition Examination Survey (NHANES III). J Gen Intern Med. (current issue)
10. Lackland DT, Woolson FR. Clinical hypertension research tools: the randomized controlled clinical trial. J Clin Hypertens. 2006;8:427-431.

11. Alderman MH, Cohen H, Madhavan S. Dietary sodium intake and mortality: the National Health and Nutrition Examination Survey (NHANES I). Lancet. 1998;351:781-785.

12. de Wardener H, MacGregor GA. Sodium and mortality (letter). Lancet. 1998;351:1508.

13. Engelman K. Sodium and mortality (letter). Lancet. 1998;351:15081509.

14. Karppanen H, Mervaala E. Sodium and mortality (letter). Lancet. 1998;351:1509. 